OPEN ACCESS

Edited by:

Patrick R. Hot

Icahn School of Medicine at Mount

Sinai, United States

Reviewed by:

Goran Simic,

University of Zagreb, Croatia

Deniz Yilmazer-Hanke,

University of UIm, Germany

*Correspondence: Lidia Alonso-Nanclares

aidi@cajal.csic.es

Received: 10 June 2019 Accepted: 28 November 2019 Published: 19 December 2019

Citation:

Furcila D, Domínguez-Álvaro $M$, DeFelipe $J$ and Alonso-Nanclares $L$

(2019) Subregional Density of Neurons, Neurofibrillary Tangles and Amyloid Plaques in the Hippocampus of Patients With Alzheimer's Disease.

Front. Neuroanat. 13:99. doi: 10.3389/fnana.2019.00099

\section{Subregional Density of Neurons, Neurofibrillary Tangles and Amyloid Plaques in the Hippocampus of Patients With Alzheimer's Disease}

\author{
Diana Furcila ${ }^{1,2}$, Marta Domínguez-Álvaro ${ }^{1}$, Javier DeFelipe ${ }^{1,2,3}$ \\ and Lidia Alonso-Nanclares ${ }^{1,2,3 *}$
}

${ }^{1}$ Cajal Laboratory of Cortical Circuits, Centre for Biomedical Technology (CTB), Universidad Politécnica de Madrid, Madrid, Spain, ${ }^{2}$ Network Biomedical Research Center on Neurodegenerative Diseases (CIBERNED), Madrid, Spain, ${ }^{3}$ Cajal Institute (CSIC), Madrid, Spain

A variety of anatomical alterations have been reported in the hippocampal formation of patients with Alzheimer's Disease $(A D)$ and these alterations have been correlated with cognitive symptoms in the early stages of the disease. Major hallmarks in $A D$ are the presence of paired helical filaments of tau protein $\left(\mathrm{PHF}_{\mathrm{Tau}}\right)$ within neurons, also known as neurofibrillary tangles (NFTs), and aggregates of amyloid- $\beta$ protein (A $\beta$ ) which form plaques in the extracellular space. Nevertheless, how the density of plaques and NFTs relate to the severity of cell loss and cognitive decline is not yet clear. The aim of the present study was to further examine the possible relationship of both $A \beta$ plaques and NFTs with neuronal loss in several hippocampal fields (DG, CA3, CA1, and subiculum) of 11 demented $A D$ patients. For this purpose, using stereological techniques, we compared neuronal densities (Nissl-stained, and immunoreactive neurons for NeuN) with: (i) numbers of neurons immunostained for two isoforms of $\mathrm{PHF}_{\mathrm{Tau}}\left(\mathrm{PHF}_{\mathrm{Tau}-\mathrm{AT} 8}\right.$ and $\mathrm{PHF}_{\text {Tau-ps396); }}$ and (ii) number of $\mathrm{A} \beta$ plaques. We found that $\mathrm{CA} 1$ showed the highest number of NFTs and A $\beta$ plaques, whereas DG and CA3 displayed the lowest number of these markers. Furthermore, $A D$ patients showed a variable neuronal loss in CA1 due to tangle-related cell death, which seems to correlate with the presence of extracellular tangles.

Keywords: amyloid- $\beta$ protein, dementia, hippocampal formation, neuronal density, plaques density, neurodegeneration, stereology

\section{INTRODUCTION}

Major hallmarks in Alzheimer's disease (AD) are the presence of paired helical filaments of tau protein $\left(\mathrm{PHF}_{\mathrm{Tau}}\right)$ within neurons, also known as neurofibrillary tangles (NFTs), and aggregates of amyloid- $\beta$ protein $(\mathrm{A} \beta)$ which form plaques in the extracellular space (GrundkeIqbal et al., 1986; Goedert et al., 1988; Avila, 2004; Hyman et al., 2012; Takahashi et al., 2017).

Abbreviations: $\mathrm{ABC}$, avidin-biotin complex; $\mathrm{A} \beta$, amyloid- $\beta$; $\mathrm{AD}$, Alzheimer's disease; $\mathrm{CA}$, cornu ammonis fields; $\mathrm{DG}$, dentate gyrus; HS, hippocampal sclerosis; -ir, immunoreactive; MTL, medial temporal lobe; NFTs, neurofibrillary tangles; $\mathrm{PHF}_{\mathrm{Tau}}$, paired helical filaments of tau protein; SD, standard deviation. 
As previously discussed in Garcia-Marin et al. (2009), plaques and NFTs are mostly found in the cerebral cortex (entorhinal cortex, hippocampal formation and neocortex), where both their number and the proportion of the cortex affected increases progressively as the disease advances (Braak and Braak, 1991; Dickson, 1997; Thal et al., 2002). These pathological changes have also been found in subcortical structures such as the amygdala, nucleus basalis, thalamus, locus coeruleus, and raphe nuclei, particularly during the late stages of AD (e.g., Esiri et al., 1997). Accordingly, multiple neuronal circuits and neurotransmitter systems may be altered in the brain of AD patients.

It has been described that these two proteins $\left(\mathrm{A} \beta\right.$ and $\left.\mathrm{PHF}_{\mathrm{Tau}}\right)$ act together and even enhance each other (DeVos et al., 2017; Polanco et al., 2017; Furcila et al., 2018), but it is still unknown which protein triggers degeneration. Their accumulation in the cerebral cortex starts at different regions; in initial stages of $\mathrm{AD}, \mathrm{PHF}_{\mathrm{Tau}}$ is seen in the medial temporal lobe (MTL; Braak and Braak, 1991), and $A \beta$ protein starts to form aggregates in neocortical regions, particularly in temporal and frontal lobe (Thal et al., 2002; Sepulcre et al., 2013). The main controversy is still whether it is $A \beta, \mathrm{PHF}_{\mathrm{Tau}}$ or their interaction that correlates with the disease progression in AD (Nelson et al., 2012; Bloom, 2014). In initial stages of the disease, a number of alterations, such as neuronal loss and changes in the pyramidal cell morphology, among others, have been reported in hippocampal regions from AD patients (Hyman et al., 1990; West et al., 2004; Merino-Serrais et al., 2011; Andrade-Moraes et al., 2013; LlorensMartín et al., 2014). AD cognitive symptoms in early stages are loss of context, disorientation and autobiographical memory impairment (Dubois et al., 2007; Petersen et al., 2009). The MTL and, in particular, the hippocampal formation and adjacent cortex support these functions (Hyman et al., 1986; Amaral and Lavenex, 2007). It is well known that a variety of changes occur in the hippocampal regions of $\mathrm{AD}$ patients, such as a decrease in the number of neurons, as well as neuronal alterations (for example; changes in the morphology of the dendritic arbor and spines); the presence of neuropil threads and $\mathrm{A} \beta$ plaques; and microvascular changes (e.g., Hyman et al., 1990; West et al., 2004; von Gunten et al., 2006; Bouras et al., 2006; Giannakopoulos et al., 2003; Andrade-Moraes et al., 2013; Llorens-Martín et al., 2014). It has been proposed that the presence of $\mathrm{PHF}_{\mathrm{Tau}}$ aggregates and $\mathrm{A} \beta$-ir plaques related to $\mathrm{AD}$ may represent a toxic environment for hippocampal neurons (Ittner and Götz, 2011). However, it has been demonstrated that CA1 neurons show a heterogeneous expression pattern of $\mathrm{PHF}_{\mathrm{Tau}}$ proteins. For example, in a previous study performed in our laboratory in CA1 regarding the co-expression of $\mathrm{PHF}_{\mathrm{Tau}-\mathrm{pS} 396}$ and $\mathrm{PHF}_{\mathrm{Tau}-\mathrm{AT}}$, we found that most (64\%) of the labeled neurons expressed only $\mathrm{PHF}_{\mathrm{Tau}-\mathrm{p} S 396}$, whereas $28 \%$ displayed both markers and $8 \%$ showed only PHF ${ }_{\text {Tau-AT8-ir }}$ (Furcila et al., 2018).

The aim of the present study was to further examine the relationship of both proteins in $\mathrm{AD}$ and possible neuronal loss in different hippocampal regions. For this purpose, we determined possible differences between regions, markers and cases, by comparing neuronal densities (Nissl-stained,

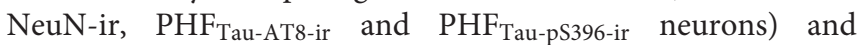
$\mathrm{A} \beta$-ir plaques.
To label PHF $\mathrm{Tau}_{\text {-ir }}$ neurons, we chose the antibody $\mathrm{PHF}_{\mathrm{Tau}-\mathrm{AT} 8}$ because it is commonly used to classify the neurofibrillary degeneration into stages known as the Braak stages (Braak et al., 2006), and the antibody $\mathrm{PHF}_{\text {Tau-pS396 }}$ because phosphorylation at site S396 is commonly related to late stages of AD (RegaladoReyes et al., 2019) and it is mostly found in NFTs (Kimura et al., 1996). For this purpose, we used stereological techniques for neurons, $\mathrm{PHF}_{\mathrm{Tau}}$ and $\mathrm{A} \beta$ plaques stainings (Nissl; NeuN; $\left.\mathrm{A} \beta ; \mathrm{PHF}_{\mathrm{Tau}-\mathrm{AT} 8} ; \mathrm{PHF}_{\mathrm{Tau}-\mathrm{pS396}}\right)$ to study the DG, CA3, CA1 and subiculum from the hippocampus of 11 demented $\mathrm{AD}$ patients.

\section{MATERIALS AND METHODS}

\section{Tissue Preparation}

Samples of human brain tissue from AD patients were obtained from 11 cases (post-mortem delay between 2:00 and 5:30 h; aged between 69 and 89 years upon death; Table 1) diagnosed with $\mathrm{AD}$ according to neuropathological examination as stated by Braak and Braak (1991) and CERAD (Mirra et al., 1991; Fillenbaum et al., 2008). These samples were obtained from two sources: Banc de Teixits Neurologics from Hospital Universitari Clinic de Barcelona (Spain) and Banco de Tejidos Fundación CIEN (Madrid, Spain), following the guidelines of the Helsinki Declaration and with the approval of the local Ethical Committees. Permission to publish the data about age and other demographic information was obtained from the patients or their next of kin along with the informed consent for use of the donor's biological samples for research, according to national regulation on biobanks. We used coronal sections of the human hippocampus at the level of the hippocampal body (Mai et al., 2016). These tissue samples have been previously used in our laboratory (Furcila et al., 2018; Regalado-Reyes et al., 2019; case codes Az1-10 correspond to BCN1-10, and Az11 to VK26). Tissue blocks containing the hippocampal formation were fixed in a solution of $4 \%$ paraformaldehyde (for $24 \mathrm{~h}$ at $\left.4^{\circ} \mathrm{C}\right)$, cryoprotected (30\% sucrose solution for at least $24 \mathrm{~h}$ ) and deep-frozen $\left(-80^{\circ} \mathrm{C}\right)$. Blocks containing the hippocampus were cut with a sliding microtome at $-40^{\circ} \mathrm{C}$ (Thermo Fischer Scientific, Waltham, MA, USA, MICROM, HM450; freeze unit, KS34, Massachusetts, USA), in serial coronal sections (50 $\mu \mathrm{m}$ thick) and collected in $0.1 \mathrm{M} \mathrm{PB}$ for further processing.

\section{Immunohistochemistry}

The sections selected from the hippocampal formation were processed for standard immunocytochemical techniques (Figure 1). Briefly, the sections were first treated to eliminate endogenous peroxidase $\left(1 \% \mathrm{H}_{2} \mathrm{O}_{2}\right)$. Those sections selected for the staining for anti-A $\beta$ were first treated with $88 \%$ formic acid (Sigma-Aldrich, No. 251364, St. Louis, MO, USA). The sections were then treated with $0.25 \%$ Triton-X in PB $0.1 \mathrm{M}, 3 \%$ horse serum (NHS, Vector Laboratories Inc., Burlingame, CA, USA) and incubated overnight at $4^{\circ} \mathrm{C}$ with a specific primary antibody. On the following day, the sections were rinsed and processed with a biotinylated secondary antibody (horse anti-mouse or goat anti-rabbit IgG, 1:200, Vector Laboratories, Burlingame, CA, USA), and then with Avidin-Biotin Complex (Vectastain ABC Kit, Vector Laboratories Inc., Burlingame, CA, USA). Staining 
TABLE 1 | Summary of clinical and pathological data.

\begin{tabular}{|c|c|c|c|c|c|}
\hline Patient & Gender & Age at disease & Braak and CERAD Scales & AD progression (years) & Postmortem delay (h:m) \\
\hline$A z 1$ & M & 80 & VI, C & 10 & $4: 30$ \\
\hline Az2 & $\mathrm{F}$ & 70 & $\mathrm{~V}, \mathrm{C}$ & 12 & $2: 00$ \\
\hline Az3 & $\mathrm{F}$ & 79 & $\mathrm{~V}, \mathrm{C}$ & 2 & $5: 30$ \\
\hline $\mathrm{Az} 4^{*}$ & $\mathrm{~F}$ & 78 & $\mathrm{IV}, \mathrm{B}$ & 9 & $5: 30$ \\
\hline Az5 & $\mathrm{F}$ & 69 & VNI, C & 14 & $4: 00$ \\
\hline Az6* & $\mathrm{F}$ & 69 & V, C & 7 & $5: 00$ \\
\hline$A z 7^{*}$ & $\mathrm{~F}$ & 89 & VI, C & - & $4: 15$ \\
\hline Az8* & $\mathrm{F}$ & 77 & VI, C & 8 & $5: 45$ \\
\hline Az9* & $\mathrm{F}$ & 76 & $\mathrm{VI}, \mathrm{C}$ & 8 & $5: 00$ \\
\hline Az10 & $\mathrm{F}$ & 71 & $\mathrm{~V}, \mathrm{C}$ & 9 & $5: 00$ \\
\hline Az11* & $\mathrm{F}$ & 82 & $V_{,}-$ & 13 & $4: 00$ \\
\hline
\end{tabular}

Braak Stages (Braak and Braak, 1991): I-II (NFTs in entorhinal cortex and closely related areas); III-IV (NFTs abundant in amygdala and hippocampus and extending slightly into the association cortex); V-VI (NFTs widely distributed throughout the neocortex and ultimately involving primary motor and sensory areas). CERAD Stages (Mirra et al., 1991; Fillenbaum et al., 2008): A (low density of neuritic plaques); B (intermediate density of neuritic plaques); C (high density of neuritic plaques). Code Az1-Az10 corresponds, respectively, to the codes BCN1-BCN10 used in previous articles from our laboratory, while Az11 corresponds to the code VK26. F, female; $h$, hours; *hippocampal sclerosis; $m$, minutes; M, male. (-) Data not available.

was visualized with the chromogen $3,3^{\prime}$-diaminobenzidine (DAB: Sigma Aldrich, St. Louis, MO, USA). All sections were incubated until they turned light brown, with the same duration of incubation for all slides; the immunostaining was checked via light microscope before stopping the reaction in all slides. Then, the sections were incubated in $0.02 \% \mathrm{OsO} 4$ in $\mathrm{PB}$ for $15 \mathrm{~s}$ at room temperature. Finally, the sections were mounted, dehydrated, cleared with Xilol and covered-slipped (DePeX; Merck KGaA 100579, 64271, Germany). The following primary antibodies were used: mouse anti-NeuN monoclonal antibody (1:2,000; Chemicon; MAB377, Temecula, CA, USA); mouse antiPHF $_{\text {Tau-AT8 }}$ monoclonal antibody (1:2,000, MN1020, Thermo Scientific, Waltham, MA, USA); rabbit anti-PHF $\mathrm{Fau}_{\mathrm{Ta}} \mathrm{p} 396$ polyclonal antibody (1:2,000, Invitrogen, 44752G, CA, EEUU); and mouse anti-A $\beta$ monoclonal antibody (clone $6 \mathrm{~F} / 3 \mathrm{D}, 1: 50$, Dako M0872, Glostrup, Denmark). Adjacent sections were Nissl-stained with toluidine blue (Figure 1).

To generate the figures, images were captured with a digital camera (Olympus DP70) attached to an Olympus BX51 light microscope (Olympus, Ballerup, Denmark) and Adobe Photoshop CS4 Extended 11.0.2 software (Adobe Systems, San Jose, CA, USA) was used to produce the figure plates.

\section{Estimation of Neuronal Densities}

Densities of labeled neurons were estimated using a stereological method known as optical dissectors (Figure 1; West and Gundersen, 1990) with the aid of Stereo Investigator software (Stereo Investigator 11.0, MicroBright Field Inc., Williston, VT, USA), using its Optical Fractionator tool. Neuronal densities, expressed as the number of labeled neurons per volume, were estimated in CA3, CA1, and subiculum, using Nissl-stained sections and NeuN-, PHF Tau-AT8- and $\mathrm{PHF}_{\text {Tau-pS396-immunostained sections. Nissl-stained and }}$ NeuN-immunostained sections were used to identify the boundaries within the hippocampus.

After randomly selecting a starting point, six sections were chosen at equally spaced intervals. Optical dissectors were made with an oil immersion $\times 100$ objective for both the NeuN-immunostained and Nissl-stained sections, on an average surface of $2,050 \mu \mathrm{m}^{2}$. The depth of the optical dissectors was $10 \mu \mathrm{m}$, rendering a study volume of $20,500 \mu \mathrm{m}^{3}$ per optical dissector. An $\times 40$ objective was used for the $\mathrm{PHF}_{\mathrm{Tau}}$ immunostained sections, on a surface of $14,450 \mu \mathrm{m}^{2}$. The depth of the optical dissectors in this case was also $10 \mu \mathrm{m}$, rendering a study volume of $144,500 \mu \mathrm{m}^{3}$. Stereological parameters for each sample and neuronal marker were chosen. Since most neurons are located in the pyramidal cell layer, neuronal densities were estimated in this layer in the CA subfields and subiculum. In Nissl-stained sections, a neuron was only counted if the nucleolus was clearly identified in the optical plane along the vertical z-axis (Figure 1).

\section{Estimations of Amyloid Plaque Density and Volume}

The number of $\mathrm{A} \beta_{\text {-ir }}$ plaques per volume was also estimated by the Optical Fractionator tool (Stereo Investigator) in DG, CA3, CA1 and subiculum (Figure 1). A minimum of six sections were selected for each patient, with equal intervals with an $\times 40$ objective on a surface of $22,500 \mu \mathrm{m}^{2}$ and with a dissector depth of $10 \mu \mathrm{m}$, rendering a study volume of $225,000 \mu \mathrm{m}^{3}$ per optical dissector.

To estimate the $A \beta$-ir plaque volume, the edges of the plaque were delineated with the Nucleator tool with the aid of Stereo Investigator software (Gundersen, 1988). This tool provides the volume of each $\mathrm{A} \beta$-ir plaque analyzed, as well as the relative volume occupied by them in each examined hippocampal subfield (Figure 1) to provide the percentage of tissue (\%) occupied by $\mathrm{A} \beta$-ir plaques.

\section{Tissue Shrinkage Estimation}

Tissue shrinkage due to staining protocols was estimated measuring the section area and thickness before and after processing to correct the final values using Stereo Investigator software. The area of the section after processing was divided by the area value measured before processing, to obtain a shrinkage factor for any area measurement. The thickness was measured at 10 random points to estimate shrinkage along the $\mathrm{z}$-axis (i.e., section compression). As a result, the brain tissue was estimated to have shrunk $30 \%$ in volume 

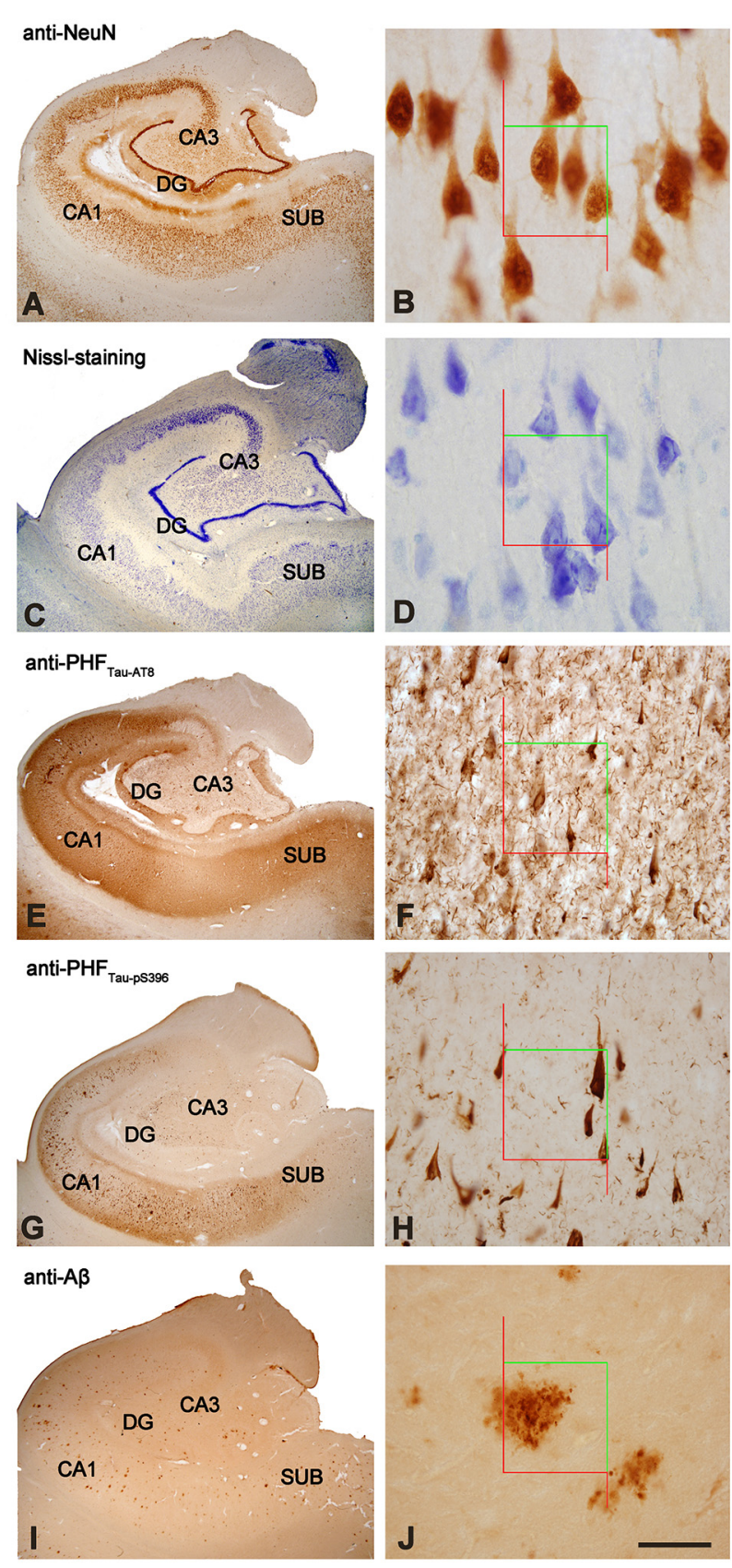

FIGURE 1 | Stained hippocampal formation sections from an AD patient. Left column, low-power microphotographs of the hippocampal formation showing NeuN-ir (A), Nissl-staining (C), PHFTau-AT8-ir (E), PHF Tau-pS396-ir (G) and $A \beta_{\text {-ir }}$ (I) sections. Right column (B, D,F,H,J), higher magnification of CA1 region to illustrate the applied counting frame (green lines correspond to the inclusion border and red lines to the exclusion border) used in the stereological procedure. Scale bar, shown in (J), indicates 1,000 $\mu \mathrm{m}$ in (A,C,E,G,I); $37 \mu \mathrm{m}$ in (B,D); $90 \mu \mathrm{m}$ in (F,H,J). DG: dentate gyrus; CA1-CA3: cornu ammonis fields; SUB: subiculum.

when processed for $\mathrm{DAB}$ and Nissl-staining: for the DABimmunostaining, the average thickness of the unstained sections was $50.2 \mu \mathrm{m}$, and after immunostaining processing, it was $16.49 \mu \mathrm{m}$ in NeuN-, $\mathrm{PHF}_{\mathrm{Tau}-}$ and $\mathrm{A} \beta$-immunostained sections; in Nissl-stained sections, the average thickness after processing was $17.4 \mu \mathrm{m}$. Thus, the final values of all stereological estimations were corrected to obtain an estimation of the pre-processing values.

\section{Statistical Analysis}

To determine possible differences between regions, markers, and cases, statistical comparisons of neuronal densities (Nisslstained, NeuN-ir, $\mathrm{PHF}_{\mathrm{Tau}-\mathrm{AT} \text {-ir }}$, and PHFTau-pS396-ir neurons) and $\mathrm{A} \beta$-ir plaque data were carried out. When the data were parametric (normality and homoscedasticity criteria were met), we performed a $t$-student test and ANOVA test, followed by Bonferroni test for pair-wise comparisons. Normality and homoscedasticity were analyzed with the Shapiro-Wilk and Levene tests, respectively. When normality and homoscedasticity were not met, we used unpaired Mann-Whitney (MW) nonparametric $U$-test and Kruskal-Wallis test (KW), followed by the Mann-Whitney test (MW) for pair-wise comparisons. Correlation analysis was used to find possible relations between variables. Statistical procedures and graphs were carried out with GraphPad Prism 7 statistical package (Prism, San Diego, CA, USA) and SPSS program (IBM SPSS Statistics v25, IBM Corporation, Foster City, CA, USA).

\section{RESULTS}

In this study, divisions of the hippocampal fields were delineated on the basis of previous descriptions (Insausti and Amaral, 2012) and nomenclature for each region was previously used in AlonsoNanclares et al. (2011). For the purposes of the present work, we will use the terms: DG, the hippocampus proper (subdivided into CA1, CA2 and CA3 fields) and the subiculum (Figure 1).

\section{Neuronal Density Estimations}

The overall neuronal density was estimated in both Nisslstained and NeuN-immunostained sections in the pyramidal layer of CA3, CA1 and subiculum (Supplementary Table S1; Figure 2A). Other hippocampal regions were not used for neuronal counting due to technical difficulties, such as the dense packing of the granular cells in the DG and the reduced volume of CA2, which produce high error coefficients that are not acceptable when obtaining accurate estimations. No differences were observed in the number of neurons per volume when comparing both markers across regions ( $T$-test: $p=0.13$ in CA3; $p=0.73$ in CA1 and $p=0.41$ in Subiculum). Neuronal densities in AD patients showed a wide range of values in all analyzed regions (Figure 2A). Moreover, estimations performed in $\mathrm{NeuN}_{\text {-ir }}$ sections displayed a higher variability than those densities obtained in Nissl-stained sections (Supplementary Table S1). Unless otherwise specified, we will refer to the data obtained in Nissl estimations for the neuronal density.

The estimated CA1 neuronal density was 8,852 $\pm 4,368$ (mean \pm SD; Supplementary Table S1). In six of the AD patients, we found a very low number of neurons in CA1, which was compatible with hippocampal sclerosis (HS), a pathological finding (Figure 3) which is often associated with 


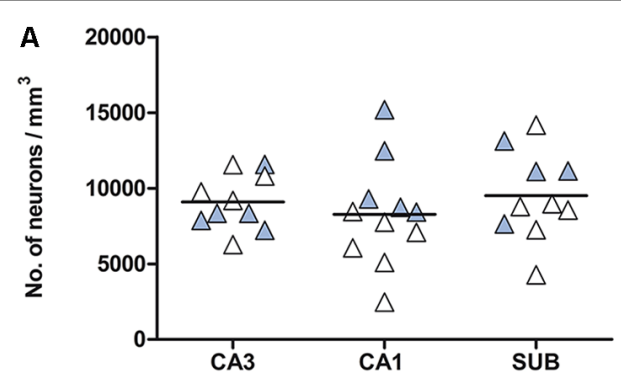

$\triangle$ Nissl-stained neurons (AD patients without $H S$ )

$\triangle$ Nissl-stained neurons (AD patients with $H S$ )

B

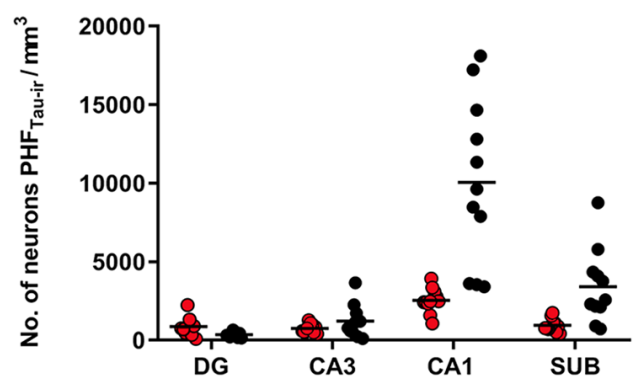

- $\mathrm{PHF}_{\text {Tau-AT8-ir }}$ neurons

- $\mathrm{PHF}_{\text {Tau-pS396-ir }}$ neurons

C

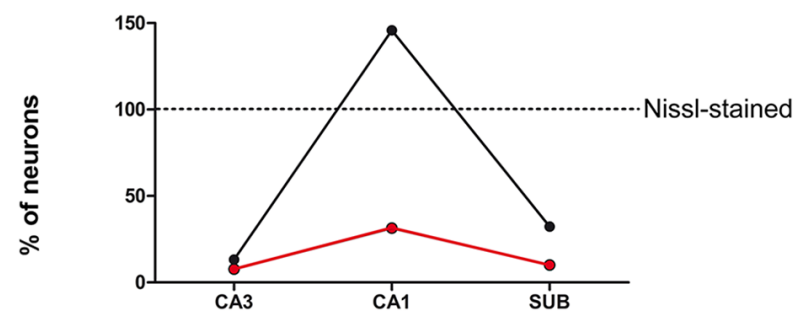

FIGURE 2 | (A) Plot showing neuronal densities in examined hippocampal areas, estimated in Nissl-stained sections. The densities represented correspond to the number of labeled neurons per volume $\left(\mathrm{mm}^{3}\right)$ for each analyzed case. White symbols correspond to the AD patients with HS. (B) Graph showing neuronal densities per volume of $\mathrm{PHF}_{\text {Tau-AT--ir }}$ and $\mathrm{PHF}_{\text {Tau-pS396-ir }}$ neurons in the hippocampal fields analyzed, in AD patients. The densities represented correspond to the number of labeled neurons per volume $\left(\mathrm{mm}^{3}\right)$ for each analyzed case. (C) Graphical representation of the percentages of PHF Tau-AT8-ir and PHF Tau-pS396-ir neurons, considering Nissl-stained neurons as the total neuronal population. Data correspond to the average percentages per region. Note that the percentage of PHF Tau-pS396-ir elements surpasses the total neuronal population, which may be a consequence of extracellular labeled NFTs or "ghost tangles" (see text for further details). HS, Hippocampal sclerosis; DG, dentate gyrus; CA1-CA3, cornu ammonis fields; SUB, subiculum.

AD (Dickson et al., 1994; Velez-Pardo et al., 2004; Attems and Jellinger, 2006; Amador-Ortiz et al., 2007). The neuronal densities found in CA1 from those $\mathrm{AD}$ patients with $\mathrm{HS}$ were $5,492 \pm 2,029$ neurons $/ \mathrm{mm}^{3}$ (mean $\pm \mathrm{SD}$ ), whereas in $\mathrm{AD}$ patients without HS they were 12,884 $\pm 2,304$ (Figure 2A). The latter values were similar to values found in CA1 from control cases (12,040 $\pm 1,746$; see "Discussion" section). No statistical differences were observed in the number of neurons per volume $\left(\mathrm{mm}^{3}\right)$ across fields (CA1, CA3, and subiculum) compared to each other (one way ANOVA; $p=0.6041 ; F=0.5132$ ).

\section{PHF $_{\text {Tau-ir Studies }}$}

To examine the presence of hyperphosphorylated tau protein in the hippocampal formation from $\mathrm{AD}$ patients, and to explore the possible correlation between $\mathrm{PHF}_{\mathrm{Tau}}$ and $\mathrm{AD}$ stages (Augustinack et al., 2002), two isoforms of $\mathrm{PHF}_{\mathrm{Tau}}$ were quantified: $\mathrm{PHF}_{\text {Tau-AT8 }}$ and $\mathrm{PHF}_{\text {Tau-pS396. }}$
In all hippocampal regions analyzed, we observed a

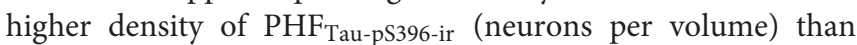

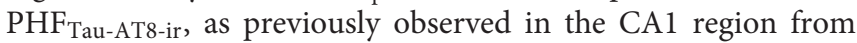
$\mathrm{AD}$ patients particularly at the advanced stages of the disease (Su et al., 1994, 1996; Kimura et al., 1996; Blazquez-Llorca et al., 2010; Furcila et al., 2018); Supplementary Table S1; Figure 2B). The highest neuronal densities of $\mathrm{PHF}_{\mathrm{Tau}-\mathrm{p} S 396-i r}$ and $\mathrm{PHF}_{\text {Tau-AT8-ir }}$ were observed in CA1, followed by the subiculum, whereas CA3 and DG presented lower values (Supplementary Table S1; Figure 2B). In addition, $\mathrm{PHF}_{\mathrm{Tau}-\mathrm{p} S 396-i \mathrm{r} \text { neuronal }}$ density was more variable between patients than $\mathrm{PHF}_{\mathrm{Tau}-\mathrm{AT} \text {-ir }}$ neuronal density, particularly in the CA1 region. Moreover, the density of $\mathrm{PHF}_{\mathrm{Tau}-\mathrm{pS} 396-\text { ir }}$ in CA1 was very close to the estimated overall neuronal densities (estimated in Nissl-stained and $\mathrm{NeuN}_{\text {-ir }}$ sections), suggesting that the majority of neurons in CA1 from $\mathrm{AD}$ patients contain $\mathrm{PHF}_{\mathrm{Tau}-\mathrm{pS} 396}$. A ratio between the number of $\mathrm{PHF}_{\mathrm{Tau}-\mathrm{ir}}$ neurons and the total neurons estimated by 


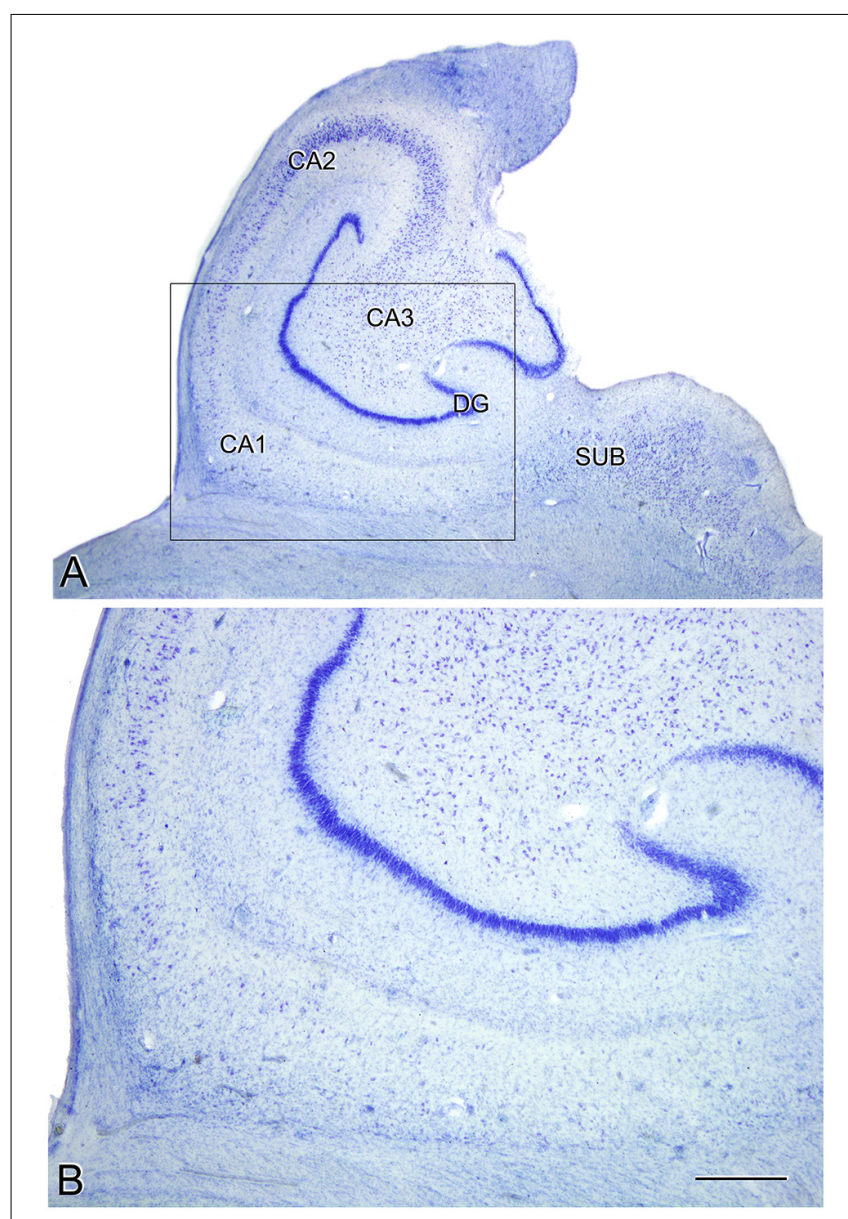

FIGURE 3 | Microphotographs of the hippocampal formation from a Nissl-stained section of an AD patient (Az9) affected by hippocampal sclerosis (A). Higher magnification of the boxed region in A shows the severe neuronal loss and gliosis in CA1 (B). DG: dentate gyrus; CA1-CA3: cornu ammonis fields; SUB: subiculum. Scale bar (in B) indicates $2.25 \mathrm{~mm}$ in (A), and $1,000 \mathrm{~mm}$ in $\mathbf{( B )}$.

Nissl-staining was calculated in CA3, CA1, and subiculum. These ratios showed that in $\mathrm{CA} 3, \mathrm{PHF}_{\mathrm{Tau}-\mathrm{AT} \text {-ir }}$ neurons represent about $8 \%$ of the total neurons, and $10 \%$ in the subiculum, whereas

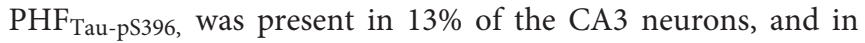
$32 \%$ of the subicular neurons. In CA1, $\mathrm{PHF}_{\text {Tau-AT8-ir neurons }}$ represent about $31 \%$ of the neurons, while this figure reached

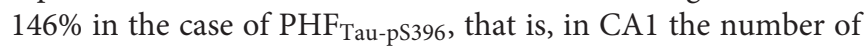
$\mathrm{PHF}_{\text {Tau-pS396-ir }}$ neurons exceeded the total number of total Nisslstained neurons by 46\% (Figure 2C; Supplementary Table S2), which could be explained by the labeling of extracellular NFTs or "ghost tangles" (see "Discussion" section).

Correlation analysis of the relative percentage of $\mathrm{PHF}_{\mathrm{Tau}-\mathrm{pS} 396}$ neurons and the total neuronal population (estimated by Nisslstaining) showed a significantly negative correlation $(P=0.0037$; $r=-0.791$; Spearman).

\section{Analyses of $\mathbf{A} \beta_{\text {-ir }}$ Plaques}

Estimation of the number of $\mathrm{A} \beta_{\text {-ir }}$ plaques per volume showed that CA1 presented the highest values, followed by the subiculum, DG and CA3 (Supplementary Table S1; Figure 4A). In addition, CA1 and subiculum not only presented the highest densities of plaques per volume ( $p<0.0001$; KW: 22.33), but they also displayed a higher proportion of tissue volume occupied by plaques ( $p=0.0002 ; \mathrm{KW}$ : 19.21; Supplementary Table S1; Figure 4B). By contrast, we found that the average volume of $A \beta_{\text {-ir }}$ plaques (Supplementary Table S1; Figure 4C) was significantly higher $(p=0.0198 ; \mathrm{KW}: 9.86)$ in the DG $\left(52,350 \mu \mathrm{m}^{3}\right)$.

In summary, DG and CA3 displayed the lowest number of plaques per volume, and although plaques in these regions were bigger, the relative volume they occupied in these regions was lower. By contrast, CA1 and subiculum presented a higher number of $\mathrm{A} \beta_{\text {-ir }}$ plaques per volume and also showed higher proportions of tissue occupied by plaques, although the plaque size was relatively small.

\section{DISCUSSION}

In the current study, we used coronal sections of the human hippocampus at the level of the hippocampal body from patients with $\mathrm{AD}$ to estimate the density of neurons, NFTs and amyloid plaques per $\mathrm{mm}^{3}$ in different hippocampal fields. The present study is based on the analysis of relatively few sections of the hippocampus from these patients; therefore, the estimation should not be extrapolated to the whole hippocampus. We found that hippocampal CA1 field was the region most affected by the presence of numerous $\mathrm{PHF}_{\mathrm{Tau}}$-ir elements and $\mathrm{A} \beta$-ir plaques, compared to other hippocampal fields of the same patients. The subiculum showed moderate levels of $\mathrm{PHF}_{\mathrm{Tau}-\mathrm{ir}}$ neurons and $\mathrm{A} \beta$ ir plaques, while DG and CA3 were less affected by the presence of these pathological elements.

\section{Neuronal Densities}

No significant differences in neuronal densities were found between the CA1, CA3 and subiculum within a given patient or between these hippocampal fields from different patients, except in AD patients with HS. A very low neuronal density was found in CA1 in the HS patients, with the density being significantly lower compared to CA3 and subiculum of the same patients as well as compared to CA1, CA3 and subiculum of the patients without HS. We examined $11 \mathrm{AD}$ cases (age range: 69-89 years old) and the neuronal density in CA1 ranged from 2,475 to 8,458 neurons $/ \mathrm{mm}^{3}$ in those cases with HS, and from 8,430 to 15,187 neurons $/ \mathrm{mm}^{3}$ in the rest of the AD patients. Although age-matched controls for comparison with the $\mathrm{AD}$ cases would clearly be ideal, it should be noted that the neuronal density range of the $\mathrm{AD}$ patients without HS was similar to the control group described in a previous study performed in our laboratory using the same methods of quantification, despite the age differences (Andrioli et al., 2007). In this Andrioli et al.'s (2007) study, three autopsy control cases were examined and the neuronal densities ranged from 10,744 to 14,024 neurons $/ \mathrm{mm}^{3}$ (age range: $49-69$ years old). Moreover, the CA3 and subiculum from AD patients displayed neuronal densities $(8,936$ in CA3; 9,503 in subiculum) that were similar to those found in these control cases $(9,852 \pm 978$ in 


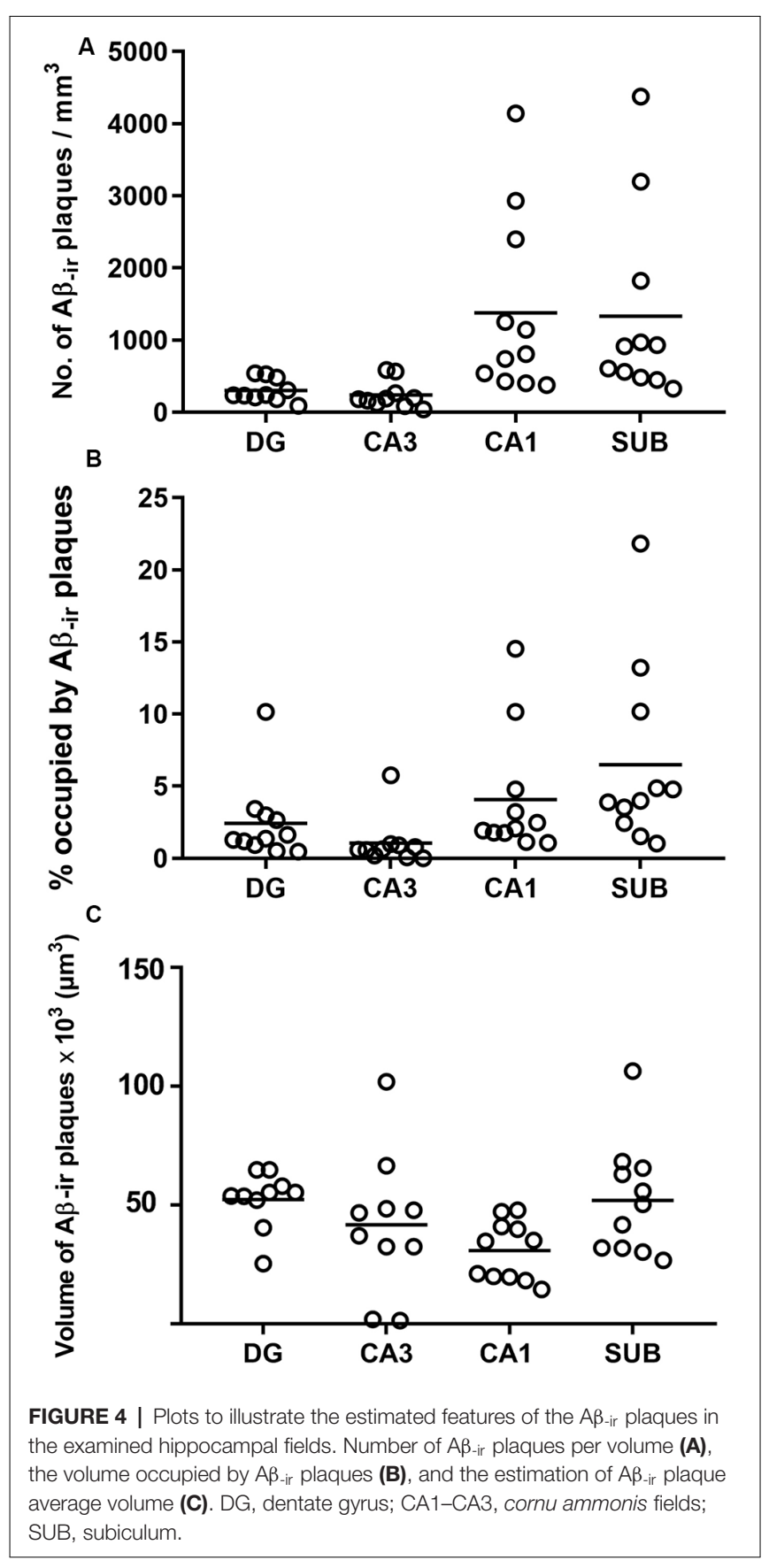

CA3; $10,186 \pm 2,672$ in subiculum). Furthermore, in the same study by Andrioli et al. (2007), the neuronal densities in the control CA1 region obtained from biopsies taken from epileptic patients (age range: 21-65 years old) were estimated to range from 11,057 to 13,194 neurons $/ \mathrm{mm}^{3}$. Therefore, although our previous studies were based on a relatively small number of cases, they did suggest that the density of neurons in the control CA1 is similar in individuals with ages ranging between 21 and 69 years old. Indeed, a rather small change $(10 \%)$ in the number of neocortical neurons was found as a function of age by Pakkenberg and Gundersen (1997) in a study which covered ages ranging from 20 to 90 years old. However, since the AD patients show brain atrophy (e.g., van de Pol et al., 2006; although we did not measure the total volume of the hippocampus), it is obvious that there is a decrease in the absolute number of neurons in $\mathrm{AD}$ patients despite the fact that that the number of neurons per $\mathrm{mm}^{3}$ was similar to that found in previously published results in healthy individuals.

The vulnerability of CA1 to neurodegeneration has been widely investigated (reviewed in Duvernoy, 2005) and it has been reported that this particular region is very susceptible to metabolic changes (reviewed in Bartsch and Wulff, 2015). The greatest reduction in neuronal density was observed in those $\mathrm{AD}$ cases which also showed HS (Table 1, Supplementary Table S1; Figure 2A), while non-sclerotic AD patients displayed higher neuronal densities in the CA1 region, with values similar to control cases (see "Results" section). Since the majority of neurons in CA1 are pyramidal cells and severe neuronal loss was found in CA1 from $\mathrm{AD}$ patients with HS, it follows that their projection sites lack their normal inputs from CA1. However, how and when neuronal loss-related to $\mathrm{AD}$ progression-impacts on the hippocampal connectivity and function remains to be elucidated.

Remarkably, in CA1, we found that the density of PHF $_{\text {Tau-pS396-ir }}$ neurons reaches the total population of $\mathrm{NeuN}_{\text {-ir }}$ neurons, and even surpasses the neuronal densities estimated in Nissl-stained sections. That is, virtually all CA1 neurons from $\mathrm{AD}$ patients were labeled by the anti- $\mathrm{PHF}_{\mathrm{Tau}-\mathrm{pS} 396}$ antibody.

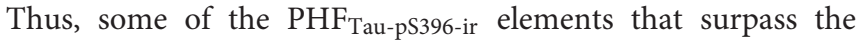
total neuronal population may correspond to extracellular labeled NFTs. In the estimations performed in Nissl-stained sections, a neuron was quantified only if its nucleus was visible; neurons that had lost their nucleus or cellular integrity were not counted. It has been reported that in $\mathrm{AD}$ patients there is a pathological degeneration of $\mathrm{PHF}_{\mathrm{Tau}-\mathrm{ir}}$ neurons, which leads to a loss of the neuronal integrity, resulting in an extracellular NFT-the so-called "ghost tangle" (Braak et al., 1994). These ghost tangles have been seen in late stages of $\mathrm{AD}$ and they are phosphorylated, mainly at Ser396 (Kimura et al., 1996). In the present study, we found that cases with low neuronal density displayed more $\mathrm{PHF}_{\text {Tau-pS396 }}$ extracellular tangles, suggesting that neuronal loss has occurred to a great extent due to $\mathrm{AD}$-related tangle pathology. This finding may provide a morphological correlate of severe cell loss in $\mathrm{AD}$, which has been referred to as hippocampal sclerosis in the literature (Dickson et al., 1994; Velez-Pardo et al., 2004; Attems and Jellinger, 2006; Amador-Ortiz et al., 2007).

Thus, in CA1 from AD patients, some of the neurons might have lost their integrity, functionality and normal connectivity. Indeed, a loss of dendritic spines and dendritic atrophy in pyramidal neurons containing well-developed NFTs has been described in AD patients (Merino-Serrais et al., 2013). So, progressive changes in the $\mathrm{PHF}_{\text {Tau-pS396-ir }}$ neurons may develop into morphological and functional alterations, and, finally, lead to a total degeneration of the neuron resulting in extracellular NFT. Moreover, it has been demonstrated that 
CA1 neurons show a heterogeneous expression pattern of $\mathrm{PHF}_{\mathrm{Tau}}$ proteins. For example, in a previous study performed in our laboratory in CA1 regarding the co-expression of $\mathrm{PHF}_{\text {Tau-pS396 }}$ and $\mathrm{PHF}_{\text {Tau-AT8 }}$ in the same patients as in the present work, we found that $64 \%$ of the labeled neurons expressed only $\mathrm{PHF}_{\mathrm{Tau}-\mathrm{p} 3396}, 28 \%$ showed both markers and $8 \%$ displayed only PHF $_{\text {TauAT8-ir }}$ (Furcila et al., 2018). Some studies have proposed that $\mathrm{PHF}_{\mathrm{Tau}-\mathrm{AT} 8}$ is a specific marker of early stages, while $\mathrm{PHF}_{\mathrm{Tau}-\mathrm{pS} 396}$ appears in late stages (Su et al., 1994, 1996; Regalado-Reyes et al., 2019). Nevertheless, other authors have suggested that $\mathrm{PHF}_{\text {Tau-pS396 }}$ occurs in the early stages and has a dynamic pattern of expression throughout the course of the disease, while $\mathrm{PHF}_{\mathrm{Tau}} \mathrm{AT}$ 8 appears in advanced stages (Mondragón-Rodríguez et al., 2014). Our results are in line with the latter study, since we found higher densities of $\mathrm{PHF}_{\mathrm{Tau}-\mathrm{pS} 396-\mathrm{ir}}$ neurons than $\mathrm{PHF}_{\mathrm{Tau}-\mathrm{AT} \text {-ir }}$ neurons in all examined AD patients (which corresponded to the IV-V stages on the Braak scale). The role of intracellular $\mathrm{PHF}_{\mathrm{Tau}}$ is an open debate; it has been suggested that its presence does not necessarily indicate severe and irreversible damage (Gong and Iqbal, 2008; Avila et al., 2012; Merino-Serrais et al., 2013; Polanco et al., 2017) and intracellular $\mathrm{PHF}_{\mathrm{Tau}}$ has been reported in CA1 neurons in non-demented elderly patients (Ferrer, 2012). However, since $\mathrm{PHF}_{\mathrm{Tau}}$ may impair the expression of another protein or proteins, and may affect the course of the disease, it is difficult to establish a hyperphosphorylation stage-dependent pattern.

\section{A $\beta$ Plaques Density}

CA1 also displayed the highest values for the density of $A \beta_{\text {-ir }}$ plaques. Previous studies in our laboratory in the CA1 of $\mathrm{AD}$ patients have shown that the presence of $\mathrm{A} \beta_{\text {-ir }}$ plaques leads to local alterations, including changes in pyramidal cell morphology and innervation (e.g., Garcia-Marin et al., 2009; Blazquez-Llorca et al., 2010; Merino-Serrais et al., 2013; AntónFernández et al., 2017). Moreover, our previous study-on $\mathrm{A} \beta$-ir plaque distribution in $\mathrm{CA} 1$-revealed that most plaques were mainly located in the stratum pyramidale followed by the stratum radiatum, suggesting that the basal and apical dendritic arborization located in these CA1 layers might be severely affected in AD (Furcila et al., 2018).

$\mathrm{A} \beta$-ir plaques have been proposed to trigger glial activation (D’Andrea et al., 2001; Jung et al., 2015; for a review see Chun and Lee, 2018), which-in turn-has been proposed to be part of the inflammatory process associated with the presence of both $\mathrm{PHF}_{\mathrm{Tau}}$ and $\mathrm{A} \beta$ in $\mathrm{AD}$ (Parbo et al., 2017). Microglial clustering has been reported in the vicinity of $A \beta_{\text {-ir }}$ plaques in neocortical tissue from $\mathrm{AD}$ patients (Serrano-Pozo et al., 2013). In particular, activated microglia may internalize $A \beta$, contributing to the stabilization of plaque size (Rajendran et al., 2006; Serrano-Pozo et al., 2013; Asai et al., 2015), but the toxicity of pathological protein forms in late stages of $\mathrm{AD}$ may cause altered microglial functionalities. If microglial cells fail to clear soluble $A \beta$, they may dump it into the extracellular space again, making the formation of more $\mathrm{A} \beta$-ir plaques possible. In the present study, we found that regions with a larger number of $A \beta_{\text {-ir }}$ plaques per volume (CA1 and subiculum) presented smaller plaques than those regions with less $\mathrm{A} \beta$ plaques (DG and CA3).

\section{Individual Variability}

Our data were derived from relatively few $\mathrm{AD}$ demented patients $(n=11)$, precluding the extrapolation of the results to the whole population of patients with $\mathrm{AD}$. Although examined patients were clinically rather homogeneous (Table 1), several characteristics should be considered regarding our current results. Our present data showed a remarkable variability in the neuronal density in the AD samples. Estimation of neuronal densities performed in Nissl-stained and NeuN-immunostained sections did not show differences in any of the analyzed regions. However, data derived from NeuN-immunostained sections showed greater variability, both between regions and patients. It has been reported that a delay in fixation of postmortem human brain tissue usually causes artifacts, such as disruptions in membrane continuity and an increase in the volume of the extracellular space, among other geometrical distortions (e.g., Tang et al., 2001). These features represent an important limitation when performing stereological counts, because the preservation of tissue volume is critical to obtain reliable estimates. Indeed, a recent study revealed that rat brain tissue undergoes significant metabolic changes that are accentuated with longer postmortem times and showed that this affects the visualization of certain antibodies, including anti-NeuN (Gonzalez-Riano et al., 2017). Quantitative studies on neuronal densities performed in human brain tissue with a large postmortem delay (up to $24 \mathrm{~h}$ ) may provide data that differ from our results (Simic et al., 1997; Andrade-Moraes et al., 2013). While the preservation of human brain tissue with large postmortem delay might be acceptable for certain qualitative observations (e.g., Simic et al., 1997; Wittner et al., 2006; Andrade-Moraes et al., 2013), it might not be suitable for comparative studies performed in different laboratories. In addition, brain tissue fixing techniques may also alter stereological estimates, as studies have revealed a reduction in immunoreactivity using formalin (Lyck et al., 2009).

The source of variability may also be attributable to the individual cognitive reserve. Cognitive reserve has been proposed as a compensatory mechanism, which serves as protection against neuronal degeneration, allowing variable numbers of $\mathrm{PHF}_{\text {Tau-ir }}$ neurons and $\mathrm{A} \beta_{\text {-ir }}$ plaques to be presented (Tucker and Stern, 2011; Lazarczyk et al., 2012; Steffener and Stern, 2012; Stern, 2012; Avila et al., 2015; Hoenig et al., 2017).

Finally, $A \beta_{\text {-ir }}$ plaques are observed in brain samples from non-demented cases, and clinical trials of $\mathrm{AD}$ therapies centered on the amyloid protein have failed to treat $\mathrm{AD}$-associated cognitive impairment; thus, the amyloid pathology may not be solely responsible for the cognitive decline observed in AD (reviewed in Anderson et al., 2017; Morris et al., 2018). Moreover, in $\mathrm{AD}$, the alterations are not only initiated by $\mathrm{PHF}_{\mathrm{Tau}}$ and $A \beta$ proteins, but probably also by the presence of other proteinopathies (Spires-Jones et al., 2017; Robinson et al., 2018). The interaction of altered proteins, and not their separate action, may modify the progression of AD. Thus, our study is in line with the idea that $\mathrm{AD}$ is not a unique entity but varies from one 
patient to another as a result of factors including-but not limited to-age, gender, co-pathologies and medical treatments.

In summary, we found that in $\mathrm{AD}$ patients $\mathrm{CA} 1$ showed the highest number of NFTs and A $\beta$ plaques, whereas DG and CA3 displayed the lowest number of NFTs and A $\beta$ plaques. Furthermore, AD patients have a variable neuronal loss in CA1 due to tangle-related cell death, which seems to correlate with the presence of extracellular tangles.

\section{DATA AVAILABILITY STATEMENT}

The datasets generated for this study are available on request to the corresponding author.

\section{ETHICS STATEMENT}

The studies involving human participants were reviewed and approved by Banc de Teixits Neurologics from Hospital Universitari Clinic de Barcelona (Spain) and Banco de Tejidos Fundación CIEN (Madrid, Spain). The patients/participants provided their written informed consent to participate in this study.

\section{AUTHOR CONTRIBUTIONS}

JD and LA-N oversaw and designed the project. DF processed the tissue. DF and MD-Á performed data acquisition and initial analysis; they prepared the figures. LA-N supervised data analysis. DF and LA-N drafted the initial manuscript. All authors revised and contributed to the final version of the manuscript.

\section{REFERENCES}

Alonso-Nanclares, L., Kastanauskaite, A., Rodriguez, J. R., Gonzalez-Soriano, J., and DeFelipe, J. (2011). A stereological study of synapse number in the epileptic human hippocampus. Front. Neuroanat. 5:8. doi: 10.3389/fnana.2011. 00008

Amador-Ortiz, C., Lin, W.-L., Ahmed, Z., Personett, D., Davies, P., Duara, R., et al. (2007). TDP-43 immunoreactivity in hippocampal sclerosis and Alzheimer's disease. Ann. Neurol. 61, 435-445. doi: 10.1002/ana.21154

Amaral, D., and Lavenex, P. (2007). "Hippocampal Neuroanatomy," in The Hippocampus Book, eds D. G. Amaral, P. Andersen, T. Bliss, R. G. M. Morris and J. O'Keefe (New York: Oxford University Press), 37-114. doi: 10.1093/acprof:oso/9780195100273.003.0003

Anderson, R. M., Hadjichrysanthou, C., Evans, S., and Wong, M. M. (2017). Why do so many clinical trials of therapies for Alzheimer's disease fail? Lancet 390, 2327-2329. doi: 10.1016/s0140-6736(17)32399-1

Andrade-Moraes, C. H., Oliveira-Pinto, A. V., Castro-Fonseca, E., da Silva, C. G., Guimarães, D. M., Szczupak, D., et al. (2013). Cell number changes in Alzheimer's disease relate to dementia, not to plaques and tangles. Brain 136, 3738-3752. doi: 10.1093/brain/awt273

Andrioli, A., Alonso-Nanclares, L., Arellano, J. I., and DeFelipe, J. (2007). Quantitative analysis of parvalbumin-immunoreactive cells in the human epileptic hippocampus. Neuroscience 149, 131-143. doi: 10.1016/j. neuroscience.2007.07.029

Antón-Fernández, A., Merchán-Rubira, J., Avila, J., Hernández, F., DeFelipe, J., and Muñoz, A. (2017). Phospho-tau accumulation and structural alterations of the golgi apparatus of cortical pyramidal neurons in the P301S tauopathy mouse model. J. Alzheimers Dis. 60, 651-661. doi: 10.3233/jad170332

\section{FUNDING}

This work was supported by grants from the following entities: the Spanish "Ministerio de Ciencia, Innovación y Universidades" (grant PGC2018-094307-B-I00); Centro de Investigación en Red Sobre Enfermedades Neurodegenerativas (CIBERNED, CB06/05/0066, Spain); Fundación por un Mañana Sin Alzheimer (León, Spain) and; the Alzheimer's Association (ZEN-15321663).

\section{ACKNOWLEDGMENTS}

We would like to thank Lorena Valdes, Carmen Alvarez and Miriam Marin for technical assistance, and G. Leon-Espinosa and $\mathrm{P}$. Merino-Serrais for their help processing the tissue. The authors would also like to thank Banc de Teixits Neurologics from Hospital Universitari Clinic de Barcelona (Dr. I. Ferrer, Servicio de Anatomía Patológica, IBIDELLHospital Universitario de Bellvitge, Barcelona, Spain) and Banco de Tejidos Fundación CIEN (Dr. A. Rábano, Área de Neuropatología, Centro Alzheimer, Fundación Reina Sofía, Madrid, Spain) for providing human brain tissue. We would also like to thank Nick Guthrie for his helpful comments and excellent editorial assistance.

\section{SUPPLEMENTARY MATERIAL}

The Supplementary Material for this article can be found online at: https://www.frontiersin.org/articles/10.3389/fnana. 2019.00099/full\#supplementary-material.

Asai, H., Ikezu, S., Tsunoda, S., Medalla, M., Luebke, J., Wolozin, B., et al (2015). Depletion of microglia and inhibition of exosome synthesis halt tau propagation. Nat. Neurosci. 18, 1584-1593. doi: 10.1038/nn.4132

Attems, J., and Jellinger, K. A. (2006). Hippocampal sclerosis in Alzheimer disease and other dementias. Neurology 66:775. doi: 10.1212/01.wnl.0000200959. 50898.26

Augustinack, J. C., Schneider, A., Mandelkow, E. M., and Hyman, B. T. (2002). Specific tau phosphorylation sites correlate with severity of neuronal cytopathology in Alzheimer's disease. Acta Neuropathol. 103, 26-35. doi: $10.1007 /$ s004010100423

Avila, J. (2004). The influence of aging in one tauopathy: Alzheimer's disease. Arch. Immunol. Ther. Exp. 52, 410-413.

Avila, J., León-Espinosa, G., García, E., García-Escudero, V., Hernández, F., and DeFelipe, J. (2012). Tau phosphorylation by GSK3 in different conditions. Int. J. Alzheimers Dis. 2012:578373. doi: 10.1155/2012/ 578373

Avila, J., Perry, G., Strange, B. A., and Hernandez, F. (2015). Alternative neural circuitry that might be impaired in the development of Alzheimer disease. Front. Neurosci. 9:145. doi: 10.3389/fnins.2015.00145

Bartsch, T., and Wulff, P. (2015). The hippocampus in aging and disease: from plasticity to vulnerability. Neuroscience 309, 1-16. doi: 10.1016/j.neuroscience. 2015.07.084

Blazquez-Llorca, L., Garcia-Marin, V., and DeFelipe, J. (2010). Pericellular innervation of neurons expressing abnormally hyperphosphorylated tau in the hippocampal formation of Alzheimer's disease patients. Front. Neuroanat. 4:20. doi: 10.3389/fnana.2010.00020

Bloom, G. S. (2014). Amyloid- $\beta$ and tau: the trigger and bullet in Alzheimer disease pathogenesis. JAMA Neurol. 71, 505-508. doi: 10.1001/jamaneurol. 2013.5847 
Bouras, C., Kövari, E., Herrmann, F. R., Rivara, C. B., Bailey, T. L., von Gunten, A., et al. (2006). Stereologic analysis of microvascular morphology in the elderly: Alzheimer disease pathology and cognitive status. J. Neuropathol. Exp. Neurol. 65, 235-244. doi: 10.1097/01.jnen.0000203077.53080.2c

Braak, H., Alafuzoff, I., Arzberger, T., Kretzschmar, H., and Del Tredici, K. (2006). Staging of Alzheimer disease-associated neurofibrillary pathology using paraffin sections and immunocytochemistry. Acta Neuropathol. 112, 389-404. doi: 10.1007/s00401-006-0127-z

Braak, H., and Braak, E. (1991). Neuropathological stageing of Alzheimer-related changes. Acta Neuropathol. 82, 239-259. doi: 10.1007/bf00308809

Braak, F., Braak, H., and Mandelkow, E.-M. (1994). A sequence of cytoskeleton changes related to the formation of neurofibrillary tangles and neuropil threads. Acta Neuropathol. 87, 554-567. doi: 10.1007/bf00293315

Chun, H., and Lee, C. J. (2018). Reactive astrocytes in Alzheimer's disease: a double-edged sword. Neurosci. Res. 126, 44-52. doi: 10.1016/j.neures.2017. 11.012

D'Andrea, M. R., Reiser, P. A., Gumula, N. A., Hertzog, B. M., and AndradeGordon, P. (2001). Application of triple immunohistochemistry to characterize amyloid plaque-associated inflammation in brains with Alzheimer's disease. Biotech. Histochem. 76, 97-106. doi: 10.1080/714028132

DeVos, S. L., Miller, R. L., Schoch, K. M., Holmes, B. B., Kebodeaux, C. S., Wegener, A. J., et al. (2017). Tau reduction prevents neuronal loss and reverses pathological tau deposition and seeding in mice with tauopathy. Sci. Transl. Med. 9:eaag0481. doi: 10.1126/scitranslmed.aag0481

Dickson, D. W. (1997). The pathogenesis of senile plaques. J. Neuropathol. Exp. Neurol. 56, 321-339. doi: 10.1097/00005072-199704000-00001

Dickson, D. W., Davies, P., Bevona, C., Van Hoeven, K. H., Factor, S. M., Grober, E., et al. (1994). Hippocampal sclerosis: a common pathological feature of dementia in very old ( $>$ or $=80$ years of age) humans. Acta Neuropathol. 88 , 212-221. doi: 10.1007/bf00293396

Dubois, B., Feldman, H. H., Jacova, C., DeKosky, S. T., Barberger-Gateau, P., Cummings, J., et al. (2007). Research criteria for the diagnosis of Alzheimer's disease: revising the NINCDS-ADRDA criteria. Lancet Neurol. 6, 734-746. doi: 10.1016/S1474-4422(07)70178-3

Duvernoy, H. M. (2005). The Human Hippocampus: Functional Anatomy, Vascularization and Serial Sections with MRI. 3rd Edn. Berlin, Heidelberg: Springer

Esiri, M. M., Hyman, B. T., Beyreuther, K., and Masters, C. L. (1997). “Aging and dementia," in Greenfield's Neuropathology, eds D. I. Graham and P. I. Lantos (London: Arnold), 153-233.

Ferrer, I. (2012). Defining Alzheimer as a common age-related neurodegenerative process not inevitably leading to dementia. Prog. Neurobiol. 97, 38-51. doi: 10.1016/j.pneurobio.2012.03.005

Fillenbaum, G. G., van Belle, G., Morris, J. C., Richard, C., Mirra, S. S., Davis, P. C., et al. (2008). Consortium to establish a registry for Alzheimer's disease CERAD: the first twenty years. Alzheimers Dement. 4, 96-109. doi: 10.1016/j.jalz.2007. 08.005

Furcila, D., DeFelipe, J., and Alonso-Nanclares, L. (2018). A study of amyloid-b and phosphotau in plaques and neurons in the hippocampus of Alzheimer's disease patients. J. Alzheimers Dis. 64, 417-435. doi: 10.3233/jad180173

Garcia-Marin, V., Blazquez-Llorca, L., Rodriguez, J.-R., Boluda, S., Muntane, G., Ferrer, I., et al. (2009). Diminished perisomatic GABAergic terminals on cortical neurons adjacent to amyloid plaques. Front. Neuroanat. 3:28. doi: 10.3389/neuro.05.028.2009

Giannakopoulos, P., Herrmann, F. R., Bussiere, T., Bouras, C., Kövari, E., Perl, D. P., et al. (2003). Tangle and neuron numbers, but not amyloid load, predict cognitive status in Alzheimer's disease. Neurology 60, 1495-1500. doi: 10.1212/01.wnl.0000063311.58879.01

Goedert, M., Wischik, C. M., Crowther, R. A., Walker, J. E., and Klug, A. (1988). Cloning and sequencing of the cDNA encoding a core protein of the paired helical filament of Alzheimer disease: identification as the microtubule-associated protein tau. Proc. Natl. Acad. Sci. U S A 85, 4051-4055. doi: 10.1073/pnas.85.11.4051

Gong, C.-X., and Iqbal, K. (2008). Hyperphosphorylation of microtubuleassociated protein tau: a promising therapeutic target for Alzheimer disease. Curr. Med. Chem. 15, 2321-2328. doi: 10.2174/092986708785 909111
Gonzalez-Riano, C., Tapia-González, S., García, A., Muñoz, A., DeFelipe, J., and Barbas, C. (2017). Metabolomics and neuroanatomical evaluation of post-mortem changes in the hippocampus. Brain Struct. Funct. 222, 2831-2853. doi: 10.1007/s00429-017-1375-5

Grundke-Iqbal, I., Iqbal, K., Tung, Y. C., Quinlan, M., Wisniewski, H. M., and Binder, L. I. (1986). Abnormal phosphorylation of the microtubule-associated protein tau (tau) in Alzheimer cytoskeletal pathology. Proc. Natl. Acad. Sci. U S A 83, 4913-4917. doi: 10.1073/pnas.83.13.4913

Gundersen, H. J. G. (1988). The nucleator. J. Microsc. 151, 3-21. doi: 10.1111/j. 1365-2818.1988.tb04609.x

Hoenig, M. C., Bischof, G. N., Hammes, J., Faber, J., Fliessbah, K., van Eimeren, T., et al. (2017). Tau pathology and cognitive reserve in Alzheimer's disease. Neurobiol. Aging 57, 1-7. doi: 10.1016/j.neurobiolaging.2017. 05.004

Hyman, B. T., Phelps, C. H., Beach, T. G., Bigio, E. H., Cairns, N. J., Carrillo, M. C., et al. (2012). National insitute on aging- Alzheimer's association guidelines for the neuropathologic assessment of Alzheimer's disease. Alzheimers Dement. 8, 1-13. doi: 10.1016/j.jalz.2011.10.007

Hyman, B. T., Van Hoesen, G. W., and Damasio, A. R. (1990). Memory-related neural systems in Alzheimer's disease: an anatomic study. Neurology 40, 1721-1730. doi: 10.1212/wnl.40.11.1721

Hyman, B. T., Van Hoesen, G. W., Kromer, L. J., and Damasio, A. R. (1986). Perforant pathway changes and the memory impairment of Alzheimer's disease. Ann. Neurol. 20, 472-481. doi: 10.1002/ana.410200406

Insausti, R., and Amaral, D. G. (2012). Hippocampal Formation. 3rd Ed. Amsterdam: Elsevier Inc.

Ittner, L. M., and Götz, J. (2011). Amyloid- $\beta$ and tau-a toxic pas de deux in Alzheimer's disease. Nat. Rev. Neurosci. 12, 65-72. doi: 10.1038/nrn2967

Jung, C. K. E., Keppler, K., Steinbach, S., Blazquez-Llorca, L., and Herms, J. (2015). Fibrillar amyloid plaque formation precedes microglial activation. PLoS One 10:e0119768. doi: 10.1371/journal.pone.0119768

Kimura, T., Ono, T., Takamatsu, J., Yamamoto, H., Ikegami, K., Kondo, A., et al. (1996). Sequential changes of tau-site-specific phosphorylation during development of paired helical filaments. Dementia 7, 177-181. doi: 10.1159/000106875

Lazarczyk, M. J., Hof, P. R., Bouras, C., and Giannakopoulos, P. (2012). Preclinical Alzheimer disease: identification of cases at risk among cognitively intact older individuals. BMC Med. 10:127. doi: 10.1186/1741-7015-10-127

Llorens-Martín, M., Blazquez-Llorca, L., Benavides-Piccione, R., Rabano, A., Hernandez, F., Avila, J., et al. (2014). Selective alterations of neurons and circuits related to early memory loss in Alzheimer's disease. Front. Neuroanat. 8:38. doi: 10.3389/fnana.2014.00038

Lyck, L., Santamaria, I. D., Pakkenberg, B., Chemnitz, J., Schrøder, H. D., Finsen, B., et al. (2009). An empirical analysis of the precision of estimating the numbers of neurons and glia in human neocortex using a fractionator-design with sub-sampling. J. Neurosci. Methods 182, 143-156. doi: 10.1016/j.jneumeth. 2009.06.003

Mai, J., Majtanik, M., and Paxinos, G. (2016). Atlas of the Human Brain. 4th Edn. San Diego, CA: Academic Press.

Merino-Serrais, P., Benavides-Piccione, R., Blazquez-Llorca, L., Kastanauskaite, A., Rábano, A., Avila, J., et al. (2013). The influence of phospho-tau on dendritic spines of cortical pyramidal neurons in patients with Alzheimer's disease. Brain 136, 1913-1928. doi: 10.1093/brain/ awt088

Merino-Serrais, P., Knafo, S., Alonso-Nanclares, L., Fernaud-Espinosa, I., and DeFelipe, J. (2011). Layer-specific alterations to CA1 dendritic spines in a mouse model of Alzheimer's disease. Hippocampus 21, 1037-1044. doi: 10.1002/hipo.20861

Mirra, S. S., Heyman, A., McKeel, D., Sumi, S. M., Crain, B. J., Brownlee, L. M., et al. (1991). The consortium to establish a registry for Alzheimer's disease (CERAD). Part II. Standardization of the neuropathologic assessment of Alzheimer's disease. Neurology 41, 479-486. doi: 10.1212/wnl.41. 4.479

Mondragón-Rodríguez, S., Perry, G., Luna-Muñoz, J., Acevedo-Aquino, M. C., and Williams, S. (2014). Phosphorylation of tau protein at sites Ser(396-404) is one of the earliest events in Alzheimer's disease and down syndrome. Neuropathol. Appl. Neurobiol. 40, 121-135. doi: 10.1111/ nan. 12084 
Morris, G. P., Clark, I. A., and Vissel, B. (2018). Questions concerning the role of amyloid- $\beta$ in the definition, aetiology and diagnosis of Alzheimer's disease. Acta Neuropathol. 136, 663-689. doi: 10.1007/s00401-0181918-8

Nelson, P. T., Alafuzoff, I., Bigio, E. H., Bouras, C., Braak, H., Cairns, N. J., et al. (2012). Correlation of Alzheimer disease neuropathologic changes with cognitive status: a review of the literature. J. Neuropathol. Exp. Neurol. 71, 362-381. doi: 10.1097/NEN.0b013e31825018f7

Pakkenberg, B., and Gundersen, H. J. (1997). Neocortical neuron number in humans: effect of sex and age. J. Comp. Neurol. 384, 312-320. doi: 10.1002/ (SICI)1096-9861(19970728)384:2<312::AID-CNE10>3.0.CO;2-K

Parbo, P., Ismail, R., Hansen, K. V., Amidi, A., Mårup, F. H., Gottrup, H., et al. (2017). Brain inflammation accompanies amyloid in the majority of mild cognitive impairment cases due to Alzheimer's disease. Brain 140, 2002-2011. doi: 10.1093/brain/awx120

Petersen, R. C., Aisen, P. S., Beckett, L. A., Donohue, M. C., Gamst, A. C., Harvey, D. J., et al. (2009). Alzheimer's disease neuroimaging initiative (ADNI): clinical characterization. Neurology 74, 201-209. doi: 10.1212/WNL. 0b013e3181cb3e25

Polanco, J. C., Li, C., Bodea, L.-G., Martinez-Marmol, R., Meunier, F. A., and Götz, J. (2017). Amyloid- $\beta$ and tau complexity-towards improved biomarkers and targeted therapies. Nat. Rev. Neurol. 14, 22-39. doi: 10.1038/nrneurol. 2017.162

Rajendran, L., Honsho, M., Zahn, T. R., Keller, P., Geiger, K. D., Verkade, P., et al. (2006). Alzheimer's disease $\beta$-amyloid peptides are released in association with exosomes. Proc. Natl. Acad. Sci. U S A 103, 11172-11177. doi: 10.1073/pnas. 0603838103

Regalado-Reyes, M., Furcila, D., Hernández, F., Ávila, J., DeFelipe, J., and León-Espinosa, G. (2019). Phospho-tau changes in the human CA1 during Alzheimer's disease progression. J. Alzheimers Dis. 69, 277-288. doi: $10.3233 /$ jad-181263

Robinson, J. L., Lee, E. B., Xie, S. X., Rennert, L., Suh, E., Bredenberg, C., et al. (2018). Neurodegenerative disease concomitant proteinopathies are prevalent, age-related and APOE4-associated. Brain 141, 2181-2193. doi: 10.1093/brain/awy146

Sepulcre, J., Sabuncu, M. R., Becker, A., Sperling, R., and Johnson, K. A. (2013). In vivo characterization of the early states of the amyloid- $\beta$ network. Brain 136 , 2239-2252. doi: 10.1093/brain/awt146

Serrano-Pozo, A., Muzikansky, A., Gómez-Isla, T., Growdon, J. H., Betensky, R. A., Frosch, M. P., et al. (2013). Differential relationships of reactive astrocytes and microglia to fibrillar amyloid deposits in Alzheimer disease. J. Neuropathol. Exp. Neurol. 72, 462-471. doi: 10.1097/nen.0b013e31829 33788

Simic, G., Kostovic, I., Winblad, B., and Bogdanovic, N. (1997). Volume and number of neurons of the human hippocampal formation in normal aging and Alzheimer's disease. J. Comp. Neurol. 379, 482-494. doi: 10.1002/(sici)10969861(19970324)379:4<482::aid-cne2>3.0.co;2-z

Spires-Jones, T. L., Attems, J., and Thal, D. R. (2017). Interactions of pathological proteins in neurodegenerative diseases. Acta Neuropathol. 134, 187-205. doi: 10.1007/s00401-017-1709-7

Steffener, J., and Stern, Y. (2012). Exploring the neural basis of cognitive reserve in aging. Biochim. Biophys. Acta 1822, 467-473. doi: 10.1016/j.bbadis.2011. 09.012
Stern, Y. (2012). Cognitive reserve in ageing and Alzheimer's disease. Lancet Neurol. 11, 1006-1012. doi: 10.1016/S1474-4422(12)70191-6

Su, J. H., Cummings, B. J., and Cotman, C. W. (1994). Early phosphorylation of tau in Alzheimer's disease occurs at Ser-202 and is preferentially located within neurites. Neuroreport 5, 2358-2362. doi: 10.1097/00001756-19941100000037

Su, J. H., Cummings, B. J., and Cotman, C. W. (1996). Plaque biogenesis in brain aging and Alzheimer's disease: I. Progressive changes in phosphorylation states of paired helical filaments and neurofilaments. Brain Res. 739, 79-87. doi: 10.1016/s0006-8993(96)00811-6

Takahashi, R. H., Nagao, T., and Gouras, G. K. (2017). Plaque formation and the intraneuronal accumulation of $\beta$-amyloid in Alzheimer's disease. Pathol. Int. 67, 185-193. doi: 10.1111/pin.12520

Tang, Y., Nyengaard, J. R., De Groot, M. G., and Gundersen, H. J. G. (2001). Total regional and global number of synapses in the human brain neocortex. Synapse 41, 258-273. doi: 10.1002/syn.1083

Thal, D. R., Rüb, U., Orantes, M., and Braak, H. (2002). Phases of A $\beta$-deposition in the human brain and its relevance for the development of AD. Neurology 58, 1791-1800. doi: 10.1212/wnl.58.12.1791

Tucker, A. M., and Stern, Y. (2011). Cognitive reserve in aging. Curr. Alzheimer Res. 8, 354-360. doi: 10.2174/156720511795745320

van de Pol, L., Hensel, A., Barkhof, F., Gertz, H., Scheltens, P., and van der Flier, W. (2006). Hippocampal atrophy Alzheimer disease: age matters. Neurology 66, 236-238. doi: 10.1212/01.wnl.0000194240.47892.4d

Velez-Pardo, C., Arellano, J. I., Cardona-Gomez, P., Jimenez Del Rio, M., Lopera, F., and DeFelipe, J. (2004). CA1 hippocampal neuronal loss in familial Alzheimer's disease presenilin-1 E280A mutation is related to epilepsy. Epilepsia 45, 751-756. doi: 10.1111/j.0013-9580.2004.55403.x

von Gunten, A., Kövari, E., Bussière, T., Rivara, C. B., Gold, G., Bouras, C., et al. (2006). Cognitive impact of neuronal pathology in the entorhinal cortex and CA1 field in Alzheimer's disease. Neurobiol. Aging 27, 270-277. doi: 10.1016/j.neurobiolaging.2005.02.008

West, M. J., and Gundersen, H. J. G. (1990). Unbiassed stereological estimation of the number of neurons in the human hippocampus. J. Comp. Neurol. 296, 1-22. doi: 10.1002/cne.902960102

West, M. J., Kawas, C. H., Stewart, W. F., Rudow, G. L., and Troncoso, J. C. (2004). Hippocampal neurons in pre-clinical Alzheimer's disease. Neurobiol. Aging 25, 1205-1212. doi: 10.1016/j.neurobiolaging.2003.12.005

Wittner, L., Henze, D. A., Záborszky, L., and Buzsáki, G. (2006). Hippocampal CA3 pyramidal cells selectively innervate aspiny interneurons. Eur. J. Neurosci. 24, 1286-1298. doi: 10.1111/j.1460-9568.2006.04992.x

Conflict of Interest: The authors declare that the research was conducted in the absence of any commercial or financial relationships that could be construed as a potential conflict of interest.

Copyright (C) 2019 Furcila, Domínguez-Álvaro, DeFelipe and Alonso-Nanclares. This is an open-access article distributed under the terms of the Creative Commons Attribution License (CC BY). The use, distribution or reproduction in other forums is permitted, provided the original author(s) and the copyright owner(s) are credited and that the original publication in this journal is cited, in accordance with accepted academic practice. No use, distribution or reproduction is permitted which does not comply with these terms. 